ISSN: $2317-8957$

Volume 6, Number 2, Dec. 2018

\title{
PROPOSTA DE NOVA EMENTA PARA DISCIPLINA DE GESTÃO AMBIENTAL DA EEIMVR/UFF
}

\author{
ROSANA RAVAGLIA ${ }^{1,2}$, RONALDO FIGUEIRÓ ${ }^{1,3,4}$, MÔNICA TEIXEIRA DA COSTA MACHADO $^{5}$
}

\author{
${ }^{1}$ Centro Universitário de Volta Redonda (UniFOA) \\ ${ }^{2}$ Associação Educacional Dom Bosco (AEDB) \\ ${ }^{3}$ Fundação Centro Universitário Estadual da Zona Oeste (UEZO) \\ ${ }^{4}$ Universidade Castelo Branco (UCB) \\ ${ }^{5}$ Universidade Federal Fluminense
}

\section{RESUMO}

Nas últimas décadas, com a constatação da necessidade urgente de atuações para mudanças de atitudes que preservassem o meio ambiente, diversos órgãos se mobilizaram, principalmente a Organização das Nações Unidas, promovendo Programas, Conferências, etc.. Concomitantemente o Brasil, atos legislativos e órgãos foram criados para manutenção e conservação ambiental. Estas ações para efetivação das mudanças pautaram-se na educação, tornando-se a educação ambiental a principal condutora deste processo rumo ao desenvolvimento sustentável. E ainda, tendo como metas desenvolver responsabilidade social na população, erradicar a pobreza e minimizar as desigualdades sociais, órgãos públicos e privados foram envolvidos. É neste contexto, que as instituições de ensino podem contribuir fornecendo um ensino de qualidade e consciência para que os profissionais desenvolvam suas atividades pautando-se em preservação ambiental e com um pensamento voltado para uma sociedade igualitária. Baseando-se nestas perspectivas, este estudo objetivou a atualização da Disciplina de Gestão Ambiental da EEIMVR/UFF, tendo como caminhos metodológicos um estudo comparativo e pesquisas qualitativas. As discussões possibilitaram perceber as expectativas, elaborar uma nova ementa e complementar o conteúdo programático. E assim, com o resultado alcançado, acredita-se ter contribuído para uma formação profissional consciente dos princípios sociais e melhoria da nação.

Palavras-chave: desenvolvimento sustentável, educação ambiental, ensino de engenharia e gestão ambiental.

\begin{abstract}
In the last decades, with the verification of the urgent necessity for actions for changing attitudes that preserve the environment, various agencies were mobilized, especially the United Nations, and promoted programs, conferences and etc. Concurrently in the Brazil, legislative acts and public agencies were created for environmental maintenance and preservation. These actions to effect the changes were based on education, and the environmental education becomes a key driver of this process towards sustainable development. In addition, in order to develop social responsibility in the population, eradicate poverty and reduce social inequalities, public and private agencies were involved. In this context, Educational Institutions can contribute by providing quality education and awareness for professionals to develop their activities based on environmental preservation and with a thought toward an egalitarian society. This study aimed to update the Discipline of Environmental Management of the EEIMVR/UFF, with methodology based on a comparative study of qualitative research. The discussions enabled to perceive the expectations, to develop a new menu and to complement the curriculum. Thus, with the result achieved, is believed to have contributed to vocational training conscious of its social principles and improving the nation's.
\end{abstract}

Keywords: sustainable development, environmental education, engineering education and environmental management.

\section{INTRODUÇÃO}

Após a constatação, por estudos desenvolvidos, de que a preservação ambiental, prioritária para a sobrevivência humana, carecia de ações urgentes, a Organização das Nações Unidas empenhou-se na realização de Confe- rências, estabelecendo programas e gerando declarações que contribuíssem não só com o meio ambiente, mas também com o desenvolvimento socioeconômico dos países.

Neste momento, vários países se compromissaram com a causa, assim como o Brasil, que criou legislações, programas e segue priori- 
zando a educação ambiental, como forma de conscientizar sua população da importância do meio ambiente.

Como em todo o movimento também estava inserida a questão econômica, pois se objetivava desenvolvimento sustentável, foram envolvidos neste processo órgãos públicos e privados, com grande influência na economia mundial.

É nesta perspectiva, de acordo com as metas estabelecidas pelo governo, que há necessidade de desenvolver uma visão ambiental nos estudantes de graduação, de modo mais específico, nos engenheiros, uma vez que sua atuação influi na forma de desenvolvimento de um país.

Para alcance deste intento, faz-se imprescindível que as Instituições de Ensino Superior estejam com seus currículos atualizados e contemplados, tanto com as percepções do mercado de trabalho quanto as dos agentes educacionais envolvidos no processo de formação.

Baseando-se neste contexto, é que este estudo teve como objetivo atualizar a Disciplina de Gestão Ambiental do Departamento de Engenharia de Produção da EEIMVR/UFF. Para tanto, foram realizados um estudo comparativo e pesquisas qualitativas, com acadêmicos, professores e profissionais de empresas.

\section{EDUCAÇÃO AMBIENTAL}

De acordo com as ações pró-ambientais, a educação deve estar direcionada para que os indivíduos ao desempenharem suas atividades profissionais tenham responsabilidade com o meio ambiente e a sociedade em seu entorno, contribuindo para inserção de valores e efetivação de mudanças.

Segundo a Lei ${ }^{\circ}$ 9.795, de 27/abril/1999, que institui a Política Nacional de Educação Ambiental, a EA é um processo que permite a construção de valores, conhecimento e mudanças de atitudes voltadas para a conservação do meio ambiente.

Pautando-se em Freire (1996), podemos dizer ainda que a educação é política, pois interfere na vida do indivíduo, tendo como perspec- ponto de vista que podemos correlacionar educação e educação ambiental, pois a educação ambiental necessita da transformação propiciada pela educação, para que o ser sinta-se parte da natureza, entendendo a importância para sua sobrevivência.

Baseando-se neste contexto de alteração comportamental, faz-se necessário um trabalho para efetivação da EA, e como é um assunto complexo, no ensino superior, o desafio se constitui em obter um caráter interdisciplinar e abrangente, construindo conhecimentos aplicáveis no exercício profissional dentro da empresa, órgãos públicos ou no monitoramento de projetos. Estas ações deverão estar ajustadas aos princípios econômicos, sociais e ambientais tão necessários às gerações futuras.

Percebe-se como de suma importância que todos os envolvidos estejam conscientes de seu papel neste processo de educação ambiental voltada para o desenvolvimento sustentável. Mas mesmo com uma pequena intervenção, tratando-se desta atualização, acredita-se ser possível atingir outras disciplinas, havendo ainda a possibilidade de se expandir para pesquisa e extensão.

\section{DESENVOLVIMENTO SUSTENTÁVEL}

Apesar do surgimento com o Relatório Bruntdland, em 1987, o conceito de desenvolvimento sustentável, passou a ser adotado como modelo por volta da década de 1990, a partir da consciência da importância de interação com o meio ambiente.

Seu conceito que abrange manter o desenvolvimento de forma que continue existindo provisão para o futuro, interliga preservação ambiental com desenvolvimento econômico, baseado em leis e normas. Consolida-se com a Conferência das Nações Unidas sobre o Meio Ambiente e Desenvolvimento, que emite a Declaração do Rio, onde estabelece que os Estados devam envidar esforços para conjugar desenvolvimento sustentável com as questões ambientais através de ensino e inovações tecnológicas. 
Esta nova visão de educação, também definida na Educação para o Desenvolvimento Sustentável, envolve as Instituições de Ensino, quando objetiva uma ação participativa integrando conceitos e ferramentas, através da interdisciplinariedade, como forma de permitir a compreensão sobre a comunidade ao seu entorno e a reflexão sobre as consequências dos seus atos em relação à preservação ambiental.

Engajados neste contexto já se encontram as empresas, que segundo a Carta Empresarial para o Desenvolvimento Sustentável, já se adequam para se tornarem lucrativas, atenderem a demanda de mercado em relação ao meio ambiente e possuírem certificação, cumprindo assim as legislações em vigor, direcionadas para esta área.

Diante desta perspectiva é que surge "economia verde" (UNEP, 2011), que é uma forma de desenvolvimento que deve ser realizada em todos os níveis: locais, regionais, nacionais e internacionais, com apoio das políticas públicas e privadas.

Uma vez que a sustentabilidade prevê a erradicação da pobreza e a promoção da justiça social, havendo necessidade de preservação e ampliação do capital natural do país, pode-se relacionar a prática da economia verde com o desenvolvimento sustentável e o papel da educação.

A educação, pela necessidade de mudança cultural e habitual em relação ao consumo, e a economia, bem como as políticas públicas, devendo interagir, na promoção de oportunidades de empregos e recursos humanos qualificados que executem suas ações pautadas em um caráter ético e reflexivo.

\section{GESTÃO AMBIENTAL}

Tendo em vista as ações direcionadas ao desenvolvimento sustentável, como explanado acima, as empresas se adequaram, passando a assumir uma função sociopolítica e direcionando suas execuções para a preservação do meio ambiente por meio da gestão ambiental, que se trata do envolvimento dos todos os setores com os problemas ambientais gerados pela empresa, fortalecendo suas atividades, reduzindo custos e abrindo possibilidade de financiamentos e investimentos.

Outro aspecto a ser trabalhado refere-se às legislações ambientais, que após implantadas e vigentes proporcionarão parâmetros a serem cumpridos, de maneira que tenham responsabilidades de priorização das dimensões de sustentabilidade.

Philippi Jr et al. (2004) e Andrade (2002), afirmam que a gestão ambiental deve envolver a aplicação de conhecimentos teóri$\cos$ e práticos em relação às questões ambientais nos processos administrativos e explicitam etapas a serem cumpridas, chamando a atenção para, principalmente, coordenação e motivação.

Sob esta ótica, as instituições de ensino superior devem estar atentas para colaborar com o desenvolvimento das políticas públicas e privadas, fazendo com que seus egressos tenham uma visão integrada, preocupando-se com a preservação ambiental e uma sociedade igualitária na execução de suas atividades profissionais.

\section{ENSINO SUPERIOR}

A Lei das Diretrizes e Bases do Ensino Nacional define as finalidades do ensino superior, com destaque para o pensamento crítico e reflexivo e formação de diplomados, desenvolvimento da pesquisa e divulgação de conhecimentos científicos, firmando assim os três pilares da educação superior: ensino, pesquisa e extensão.

Uma formação bem direcionada proporcionará a visão de uma sociedade mais justa, preocupada em dispor recursos para as gerações futuras e sob este aspecto não podemos deixar de citar Kramaer (2009) que diz que o DS procura, nas Universidades, um agente para liderar o caminho, porque sua missão é a "formação de decisores do futuro" e como propulsora do conhecimento, pode alcançar além das fronteiras.

Acreditamos, perante as pesquisas realizadas, que as Universidades tendo em vista os 
compromissos assumidos nas diversas Declarações e Cartas geradas em diversas épocas, cada vez mais demonstram a vontade de fazer um futuro diferente para as novas gerações.

No documento Desafios e Perspectivas da Educação Superior Brasileira para a Década 2011-2020, destacam-se pontos cruciais a serem debatidos para melhoria da qualidade do ensino, entre eles o de formar inteligências na perspectiva de uma cidadania social e ambientalmente responsável, e situar a educação, no sentido amplo.

A Recomendação ${ }^{\circ} 10$, da Conferência de Tbilisi, menciona que uma vez que os atos praticados pelos profissionais de engenharia, repercutem no meio ambiente, mesmo que de forma indireta, deve haver o cuidado com a elaboração e aplicação dos programas educacionais, bem como as metodologias empregadas.

Com um olhar atual, de globalização, inserção de inovações e o intercâmbio, é possível verificar que os engenheiros necessitam que sua formação seja realizada com complementações pedagógicas e de conhecimentos diferenciados para que tenham capacidades multidisciplinares e enorme domínio de conhecimentos, buscando além dos bancos escolares a visão ampliada de sua atuação, para isto sendo necessário a implantação de novas metodologias de ensino e constantes revisões curriculares.

\section{METODOLOGIA}

Este estudo foi desenvolvido baseado em estudos teóricos, sendo necessário seu desmembramento em partes para uma melhor análise. As etapas executadas se deram através de um estudo comparativo e de pesquisas qualitativas.

Para realização do estudo comparativo utilizou-se as ementas dos Cursos de Graduação em Engenharia, disponíveis nos sites das Universidades, voltadas para o tema em questão, abrangendo todas as regiões do país.

As pesquisas qualitativas foram aplicadas à professores que lecionaram ou lecionam a citada Disciplina, e os que abordavam o tema meio ambiente, quando lecionavam suas disciplinas e às empresas que empregam ou empregaram os profissionais advindos da EEIMVR e aquelas que nos acenaram com contatos.

A compilação dos dados destas pesquisas se deu pelo método de Análise de Conteúdo proposta por Laurence Bardin.

Como uma melhor forma de entendimento do objeto deste estudo, cabe ressaltar que a EEIMVR foi criada em 1961, funcionando somente o eixo profissional do Curso de Graduação em Engenharia Metalúrgica. A partir de 1968, passa a integrar a Universidade Federal Fluminense, como uma de suas Unidades, adotando o nome de Escola de Engenharia Industrial Metalúrgica de Volta Redonda (EEIMVR).

Nesta época, para integralização de seu currículo, acrescenta-se a Disciplina de Ecologia I, que com o decorrer dos anos sofreu diversas atualizações.

Possui atualmente 04 (quatro) Cursos de Graduação em Engenharia, sendo estes: Mecânica, Metalúrgica, Produção e Agronegócios. A Disciplina de Gestão Ambiental foi inserida na grade curricular em 2000, e sua última atualização ocorreu em 2005.

\section{APRESENTAÇÃO E ANÁLISE DE RE- SULTADOS}

Esta análise inicia-se pelo estudo comparativo, sendo utilizadas de duas a três Universidades por regiões do país, excetuando-se os Cursos de Engenharia Ambiental ou similares, tendo em vista as especificidades de seus currículos.

\subsection{Estudo Comparativo}

Este estudo foi desenvolvido em duas etapas: pesquisa das grades curriculares e realização dos estudos comparativos empregandose tabela dinâmica, disponível no Programa "Microsoft Office Excel 2007". Para esta utilização, fez-se necessário numerar a ementa da EEIMVR partindo do "10" ao " $n$ " (quadro 7.1.1). 
Quadro 7.1.1: Numeração dos Temas da Ementa da Disciplina de Gestão Ambiental da EEIMVR

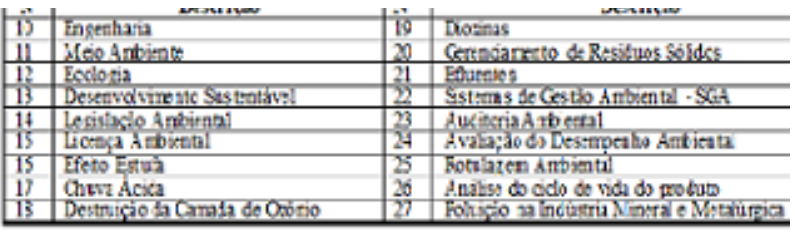

Como esta comparação tem com objetivo específico subsidiar a elaboração da nova ementa, foi utilizado o tópico da ementa, conforme apresentado no quadro 7.1.1.

\section{REGIÃO SUDESTE}

Foram utilizadas na comparação as ementas: da Universidade Federal do Rio de Janeiro - UFRJ nas localidades: Rio de Janeiro e Macaé, Universidade Federal Rural do Rio de Janeiro - UFRRJ, Universidade Federal Fluminense - UFF na localidade: Niterói, Universidade Estadual de Campinas - UNICAMP, Universidade de São Paulo - USP, Universidade Federal de Minas Gerais - UFMG, Universidade Federal de Ouro Preto - UFOP, Universidade Federal de Viçosa - UFV, Universidade Federal do Espírito Santo - UFES.

Destas 10 (dez) Instituições pesquisadas, percebeu-se que não abordam o tópico Engenharia - 05 (cinco), Desenvolvimento Sustentável - 03 (três), Legislação Ambiental, Licença Ambiental, Licença Ambiental, Efeito Estufa, Chuva Ácida, Destruição da Camada de Ozônio e Dioxinas - 01 (uma).

E foram detectados novos temas que não constavam na ementa da EEIMVR: Ecodesenvolvimento, Sistemas de Saneamento, Estudo de Caso, Reutilização da água, Noções e Efeitos da Poluição na Saúde Pública.

\section{REGIÃO SUL}

Neste comparativo foram usados os tópicos das ementas das seguintes Universidades: Universidade Federal do Rio Grande do Sul - UFRGS, Universidade Federal do Pampa
- UNIPAMPA, Universidade Federal do Paraná - UFPR, Universidade Estadual do Oeste do Paraná - UNIOESTE, Universidade Federal de Santa Catarina - UFSC, Universidade do Estado de Santa Catarina - UDESC.

Observou-se que das 06 Universidades, 03 (três) não abordam o tópico Engenharia, 02 (duas) Desenvolvimento Sustentável, 01 (uma) Legislação Ambiental, Licença Ambiental, Efeito Estufa, Chuva Ácida e Camada de Ozônio, 04 (quatro) Dioxinas, 01 (uma) Gerenciamento de Resíduos Sólidos e Efluentes e nenhuma delas Poluição na Indústria Mineral e Metalúrgica.

Ainda foi possível perceber que uma das Universidades aborda os tópicos: Sistemas de Saneamento e Saúde Pública, já detectados anteriormente. Novos tópicos foram observados: Eco-design, Produção mais limpa, Norma ISO 19011, Política de Créditos de Carbono e Radiação.

\section{REGIÃO CENTRO-OESTE}

Nesta etapa foram utilizadas as Universidades Federais de Mato Grosso - UFMT, do Mato Grosso do Sul - UFMS, de Goiás - UFG e de Brasília - UNB, Instituto Federal de Educação, Ciência e Tecnologia Goiano - IF Goiano, Pontífica Universidade Católica de Goiás - PUC Goiás, Instituto Federal de Educação, Ciência e Tecnologia de Mato Grosso - IFMT.

Foram percebidas que 02 (duas) Instituições não abordam o tópico Engenharia, 01 (uma) Ecologia, Desenvolvimento Sustentável, Licença Ambiental, 02 (duas) Dioxinas, 01 (uma) Gerenciamento de Resíduos Sólidos e Efluentes, Sistema de Gestão Ambiental, Auditoria Ambiental, Avaliação de Desempenho Ambiental, Rotulagem Ambiental e Análise do Ciclo de Vida, sendo que não há Instituição que aborde o tópico Poluição na Indústria Mineral e Metalúrgica.

Dos que já foram listados que não constam na ementa da EEIMVR, foi possível observar: 01 (uma) Instituição aborda Sistemas de Saneamento, 02 (duas) Estudo de Caso, 
02 (duas) Saúde Pública e 01 (uma) Produção mais limpa. Observou-se novos tópicos: Educação Ambiental em 04 (quatro) Universidades e Energia Renovável em 02 (duas).

\section{REGIÃO NORDESTE}

Nesta parte, foram utilizadas somente Universidades Federais, num total de 11 (onze): da Bahia - UFBA, do Ceará - UFC, do Rio Grande do Norte - UFRN, da Paraíba - UFPB, do Maranhão - UFMA, de Sergipe - UFS, Rural de Pernambuco - UFRPE, de Pernambuco - UFPE, do Piauí - UFPI, de Alagoas - UFAL, de Campina Grande - UFCG.

Foram detectados que, não abordam os tópicos: Engenharia - 02 (duas) Universidades, Desenvolvimento Sustentável - 03 (três), Legislação Ambiental e Licença Ambiental - 01 (uma), Gerenciamento de Resíduos Sólidos - 03 (três), Efluentes - 02 (duas), Sistemas de Gestão Ambiental, Auditoria Ambiental, Avaliação de Desempenho Ambiental, Rotulagem Ambiental e Análise do Ciclo de Vida do Produto - 01 (uma) e 01 (uma) Universidade aborda o tópico Dioxinas e nenhuma, Poluição na Indústria Mineral e Metalúrgica.

Dos tópicos anteriormente detectados como novos, constatamos: 03 (três) Instituições abordam Estudo de Caso, 01 (uma) Reutilização da água e Saúde Pública, 02 (duas) Produção mais Limpa, 01 (uma) Radiação, 03 (três) Educação Ambiental e Energia Renovável. Outros temas novos também foram percebidos: Selo Verde, Ecoeficiência e Metodologia Multicritério.

\section{REGIÃO NORTE}

Nesta última comparação, foram utilizadas as Universidades Federais: do Amazonas - UFAM, de Rondônia - UNIR, de Roraima UFRR, do Pará - UFPA, do Acre - UFAC e do Tocantins - UFT. Ressaltamos que o único Estado a não ser citado no processo foi o Amapá, tendo em vista que nem a Universidade Federal e nem a Estadual disponibilizam em seus "sites" as ementas das disciplinas.
Dentre as 06 (seis) Universidades pesquisadas, 02 (duas) não abordam o tema Engenharia, 03 (três) Desenvolvimento Sustentável, 02 (duas) Gerenciamento de Resíduos Sólidos e Efluentes, 02 (duas) Sistemas de Gestão Ambiental, Auditoria Ambiental, Avaliação de Desempenho Ambiental, Rotulagem Ambiental e Análise do Ciclo de Vida do Produto. Nenhuma delas abordam Dioxinas e Poluição na Indústria Mineral e Metalúrgica.

Dos tópicos já detectados anteriormente, observou-se: 01 (uma) aborda Ecodesenvolvimento, 01 (uma) Estudo de Caso, 01 (uma) Reutilização da Água e 01 (uma) Eco-design, 02 (duas) Produção mais limpa, 01 (uma) Radiação, 03 (três) Educação Ambiental e 01 (uma) Energia Renovável. Somente um novo tópico foi observado: Reciclagem de Materiais.

\section{Pesquisa Qualitativa}

\begin{tabular}{lcclr}
\multicolumn{2}{c}{ Estas } & pesquisas & foram & real- \\
izadas & com & diferentes & grupos: & pro- \\
fessores & e & profissionais & de empresas.
\end{tabular}

PESQUISA COM PROFESSORES QUE LECIONAM OU LECIONARAM A DISCIPLINA DE GESTÃO AMBIENTAL

De2005a2013,10(dez)professoreslecionaram a Disciplina, sendo que $90 \%$ participaram desta pesquisa, tendo optado, em sua maioria, por responderem seus questionários sem a presença do pesquisador, com entrega a posteriore.

Como já mencionado anteriormente sobre a importância da Disciplina, foi questionado se os professores percebiam interesse nos alunos pelo conteúdo, sendo $33,33 \%$ que sim e $22,23 \%$ na maioria dos casos. Os outros, $33,33 \%$ disseram que a consciência e o reconhecimento da importância aparecem ao longo da abordagem e $11,11 \%$ que há falta de interesse por imaturidade e pouco conhecimento básico.

Com a intenção de subsidiar a atualização da ementa, foi perguntado se sentiam falta de algum conteúdo quando lecionaram a Disciplinam sendo que $77,78 \%$ detectaram a existência de uma lacuna, o que reafirma o objetivo 
deste estudo.

Caso a resposta fosse afirmativa, solicitou-se que relacionassem o(s) conteúdo(s). Os citados foram: Ecoeficiência, Matriz Energética Brasileira e Mundial, Métodos de remediação e mitigação dos impactos ambientais, Poluentes Orgânicos Persistentes (POPs), Protocolo Internacional, Sustentabilidade e 3R's (Reduzir, Reutilizar e Reciclar), que foi duplamente mencionado.

Como subsídio para atualização da ementa foi pedido que sugerissem temas, sendo que se sobrepuseram alguns conteúdos anteriormente abordados quando da solicitação do que sentiram falta na aplicação da Disciplina, conforme quadro 7.2.2.1.

Quadro 7.2.1.1: Novos tópicos apontados pelos professores que lecionam ou lecionaram a Disciplina.

\begin{tabular}{|c|c|c|}
\hline$\Omega$ cesos Laternations & 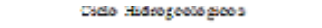 & Crodits andestass \\
\hline Eecesioinas & 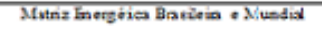 & Zadiotridido \\
\hline Preanda de Cannono & 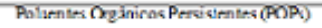 & Servipos a mossionemics: \\
\hline Protacoio Intemacion: & $\begin{array}{c}\text { Techologas de remedacto d mitigacho it } \\
\text { inpactos antientais }\end{array}$ & $\begin{array}{c}\text { 3R's Redozi, Reutilize } \\
\text { Redidar }\end{array}$ \\
\hline Tnbutaço antiental & Toxichdes bo substinchas quimicas & Sastet tabilidado \\
\hline
\end{tabular}

PESQUISA COM PROFESSORES QUE ABORDAM O TEMA MEIO AMBIENTE QUANDO MINISTRAM SUAS DISCIPLINAS

Atualmente a EEIMVR conta em seu quadro docente com 95 (noventa e cinco) professores distribuídos em 05 (cinco) Departamentos de Ensino. Destes 28 (vinte e oito) abordam o tema meio ambiente quando ministram suas disciplinas, sendo que responderam ao questionário 22 (vinte e dois) professores.

Com o intuito de verificar se a abordagem era complementar como forma de inserção da interdisciplinaridade, uma vez que a preservação do meio ambiente deve estar presente continuamente na formação do educando, foi requerido que justificasse o motivo de abordar o tema, sendo que todos os professores citaram a correlação entre o conteúdo da disciplina e o tema.
Tendo em vista que para o exercício profissional a contextualização adequada, através da troca de experiências e transmissão de conhecimento é uma forma de abranger o todo, foi questionada qual a importância e o tipo de abordagem para o conteúdo da disciplina ministrada, tendo sido citado por todos os respondentes a conscientização dos acadêmicos (importância) e a correlação do conteúdo ministrado com os impactos ambientais.

$\mathrm{Na}$ expectativa de subsidiar a atualização da Disciplina de Gestão Ambiental, foi solicitada sugestão de tema(s) a ser inserido. Alguns professores esclareceram que desconheciam a ementa, por esta razão, alguns tópicos se repetem, de acordo com a ementa utilizada, conforme quadro 7.2.2.1.

Quadro 7.2.2.1: Novos tópicos apontados pelos professores que abordam o tema Meio Ambiente.

\begin{tabular}{|c|c|c|}
\hline 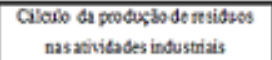 & $\begin{array}{c}\text { Uso be maledizis na geracio de } \\
\text { energia elitrica }\end{array}$ & Mariz Energitica \\
\hline 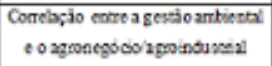 & 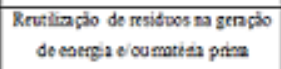 & $\begin{array}{c}\text { Caloulo dos cridines de } \\
\text { cetbono }\end{array}$ \\
\hline $\begin{array}{c}\text { Fiovofa 3 Rs (Redure, Reodar o } \\
\text { Beusing) }\end{array}$ & 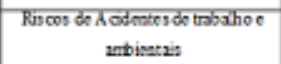 & Masuteço houstial \\
\hline 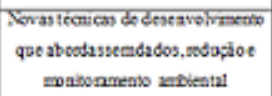 & $\begin{array}{c}\text { Tramrento de exjetros de banios de } \\
\text { extropotipis do matait }\end{array}$ & $\begin{array}{l}\text { Bedidgeal de } \\
\text { polimetet }\end{array}$ \\
\hline 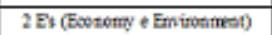 & Ergooomia & \\
\hline
\end{tabular}

\section{PESQUISA COM EMPRESAS}

Com o objetivo de identificar os anseios das empresas em relação aos profissionais advindos da EEIMVR, foram consultadas 30 (trinta) empresas de diversas regiões do país. Dentre as consultadas e as que demonstraram interesse somente 08 (oito) responderam o questionário encaminhado.

Foi perguntado aos profissionais respondentes se quando nossos engenheiros eram admitidos na empresa, era detectável a necessidade de reforçar algum conteúdo. Sendo respondido que, de acordo com a área de formação e de atuação, haveria algumas abordagens a serem levadas em maior consideração, sem, contudo relacionar diretamente este reforço 
com os profissionais advindos da EEIMVR.

No sentido de detectar com maior abrangência os conhecimentos que estes acadêmicos deveriam ter apreendido, foi questionado qual a expectativa da empresa, em relação aos itens: Sustentabilidade, Legislação, Gerenciamento de Resíduos, Sistemas de Gestão, Lixo Eletrônico e outros, sendo que todas expectativas levantadas pelos respondentes relacionavam-se à conscientização ambiental.

Por ser o local de captação e atuação de profissionais e com o objetivo de atendê-las, foi solicitado que sugerissem tema(s) a ser inserido, quadro 7.2.4.1

Quadro 7.2.3.1: Novos tópicos apontados pelas empresas

\begin{tabular}{|c|c|c|}
\hline 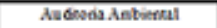 & Conservagle e Recuptroplo anbitatul & Perioa Alabitental \\
\hline Estudo de lappesto Antinetd & 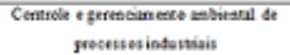 & $\begin{array}{l}\text { Gestibe \&t Proptcos } \\
\text { Antimenis }\end{array}$ \\
\hline 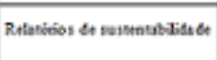 & 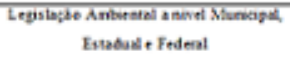 & 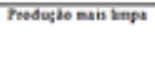 \\
\hline Logities Revers & & \\
\hline
\end{tabular}

\section{DISCUSSÃO}

Com o objetivo de identificar a composição de uma nova ementa, esta discussão teve como objetivo estabelecer um paralelo entre os tópicos da ementa utilizada e a análise dos resultados.

A partir da análise de resultados, o tópico "Engenharia" foi citado na ementa dos Cursos pesquisados por $77,5 \%$ das Instituições, enquanto que o "Meio Ambiente" por 100,00 \%. As empresas fazem uma correlação entre a Engenharia e o Meio Ambiente, para conscientização de um trabalho conjunto com envolvimentos de todos os colaboradores e os professores se preocupam quando relacionam suas disciplinas com os impactos ambientais, demonstrando a importância da engenharia para o meio ambiente, o que comprova que deve haver continuidade dos temas.

Segundo Silva et al. (2010), os engenheiros são importantes nos contextos empresarial e industrial para impulsionar projetos que abram perspectivas dentro das organizações, alinhando os planos ambientais aos negócios de uma forma estratégica.

Com referência ao tópico "Ecologia", 97,50\% das Instituições abordam o tema e pelos professores que ressaltaram a importância dos processos de sucessão ecológica. A Ecologia não pode deixar de ser abordada, tendo em vista que é através deste conteúdo, que os engenheiros conseguirão estabelecer as inter-relações existentes entre os organismos, seus meios físicos e as propostas para um planejamento ambiental. Segundo Zitske (2002), conhecer o ambiente em sua totalidade, do ecossistema aos problemas gerados pela presença do homem, é fundamental para uma mudança de atitude, gerando responsabilidades e uma ação que satisfaça a sociedade atual.

O "Desenvolvimento Sustentável” (DS), consta nas ementas de $70 \%$ das Instituições. Sustentabilidade também foi tema sugerido por professores que não conheciam a ementa, enquanto outros alegaram que a responsabilidade social é fator preponderante para o DS. Dentre os questionamentos das empresas, em relação à sustentabilidade, estas ressaltaram a importância de mudança comportamental, com multiplicação de conscientização, melhoria da qualidade de vida e o relacionamento com a comunidade ao seu entorno.

A Década da Educação das Nações Unidas para o Desenvolvimento Sustentável (ONU/ EDS, 2005) preconizam este tema como de extrema importância, pois a EDS coloca que "todos os alunos de curso superior devem entender a importância da diversidade e da inclusão", adotando valores e éticas, “...no contexto da informação".

Quanto ao tópico "Legislação Ambiental", este é abordado por $92,50 \%$ das Instituições e "Licenciamento Ambiental", abordado por $73,46 \%$ das Instituições.

Com referência à legislação foi citado pelas empresas como um conteúdo que deveria ser reforçado e inserido, caso não fizesse parte da ementa. Quanto ao Licenciamento, levantam a questão das implicações no que se refere a impacto e controle dos processos. Os professores levantam a importância da regulamentação 
e normas ambientais. Com estes, os futuros engenheiros podem alcançar melhor prática profissional, abrangendo questões conjunturais à problemática ambiental.

Phillipi Jr. et al. (2004, p. 634) diz que "não há o que não esteja relacionado ao meio ambiente e, logo, precise, sob ao menos um aspecto, sofrer influências das leis e princípios que regulam o uso dos recursos naturais".

Os tópicos "Efeito Estufa", "Chuva ácida" e "Camada de Ozônio" foram encontrados nas ementas de $95 \%$ das Instituições. Os professores preocupam-se com os impactos e controle da poluição do ar, água e solo, reforçando estes conteúdos, objetivando o desenvolvimento de processos alternativos. Utilizam também de exemplificações através de casos reais, apoiando assim as questões levantadas pelas empresas quando dizem que os profissionais deveriam ter conhecimento para solução, atendimento e redução de acidentes e impactos ambientais. Sendo que sugeriram para inclusão, Estudo do impacto ambiental e Conservação e recuperação ambiental, já abordados no Conteúdo Programático.

Poluição do solo, água e ar, apesar de não fazerem parte da ementa e sim do conteúdo programático foi tema sugerido pelos professores. Pelas pesquisas realizadas acatamos esta sugestão, passando a fazer parte da nova ementa.

"Dioxinas" foi um tópico com menor abordagem pelas Instituições, com 42,50\%. As empresas citaram a necessidade de avaliação dos impactos gerados pelas atividades industriais, bem como técnicas de gerenciamento e controle. Os professores sugeriram a inserção de Toxicidades de substâncias químicas e de Tecnologias para remediação e mitigação dos impactos ambientais e um de outro grupo sugeriu a exclusão do tema, com substituição por Poluentes Orgânicos Persistentes (POPs), tendo em vista a justificativa para substituição e uma pesquisa bibliográfica, optou-se pela troca, pois os Poluentes Orgânicos abrangem uma série de compostos tóxicos, estando dentre eles a dioxina.
A Convenção de Estocolmo sobre os POPs determina aos Países Parte a adoção de medidas para controle de todo o ciclo de vida dos POPs até sua completa eliminação, tendo em vista suas propriedades tóxicas e os problemas que estas substâncias acarretam à saúde e ao meio ambiente (ONU/PNUMA, 2004).

Das Instituições pesquisadas, 82,50 \% abordam "Gerenciamento de Resíduos Sólidos". Dentre os professores, a Reciclagem, os 3R's e o Reaproveitamento de embalagens é amplamente citado pela importância de reutilização e descarte.

Tendo em vista a importância do tema, alguns professores sugeriram a inserção na atualização da disciplina de Resíduos Sólidos de Tecnologia de Informação, Tratamento de Rejeitos de Banhos de Eletroposição de Metais e Lei dos Resíduos Sólidos. A Lei n ${ }^{\circ} 12.305$ e os temas já estão inseridos no Conteúdo Programático.

Como a questão da geração de resíduos é um problema ambiental de grandes proporções, as empresas têm como expectativa que estes acadêmicos possam ser detentores de conhecimentos para uma aplicação correta na segregação de resíduos, e identificar as possibilidades de melhoria para redução do passivo ambiental . "Efluentes" é abordado por $85 \%$ das Instituições, na correlação dos professores, estes ressaltam o compromisso profissional de controle e gerenciamento dos processos com preservação ambiental As empresas também citam as implicações legais quanto aos impactos ambientais dos efluentes na implantação de processos e produtos.

Duas Normas Brasileiras são reguladoras dos Resíduos Sólidos e da Geração de Efluentes, as NBR's 10004:2004 e 9800:1987, e as empresas as inserem no SGA.

Segundo Andrade et al. (2002) para adoção de um modelo de Gestão Ambiental é necessário que a organização tenha uma visão global e abrangente, considerando as relações de causa e efeito e a inter-relação entre recursos e valores. Os tópicos "Sistemas de Gestão Ambiental - SGA", "Avaliação do Desempenho 
Ambiental" e "Rotulagem Ambiental" são mencionados por $90 \%$ das Instituições. As empresas têm como expectativa que os profissionais sejam capazes de desenvolver, aprimorar e encaminhar políticas ambientais, utilizando ferramentas de SGA. Sugeriram a inserção de Gestão de projetos ambientais e Relatórios de sustentabilidade, mas estes temas podem fazer parte do Conteúdo Programático.

Os professores correlacionam suas disciplinas com foco na Gestão de Pessoas e Ambiente, chamando a atenção para os aspectos principais de Gestão Ambiental e a Segurança do Trabalho. Sugeriram para inserção, a Correlação entre a Gestão ambiental e o Agronegócio/Agroindustrial, no entanto acredita-se que o Professor da Disciplina já remeta esta correlação tendo em vista lecionar para o Curso de Agronegócios; e a Norma NBR ISO 14.001, que já é abordada na ementa.

Andrade et al. (2002, p. 200), em uma análise da empresa perante aos projetos ligados às decisões ambientais, coloca que "os profissionais formados pelas instituições de ensino" devem ter uma visão mais ampliada da empresa, além do operacional.

"Auditoria Ambiental" e "Análise do Ciclo de Vida do Produto" é abordado na ementa de $87,50 \%$ das Instituições. Por não conhecerem a ementa, dentre os temas sugeridos pelas empresas está Auditoria Ambiental e Perícia Ambiental. Estas também têm como expectativa que os profissionais ao implementarem o projeto de um novo produto levem em conta todo o ciclo de vida do mesmo, solicitando que a Análise do Ciclo de Vida do Produto tenha o conteúdo constantemente reforçado, conforme preconiza os estudos da nova DCN para os cursos de engenharia (ABENGE, 2018).

"Poluição na Indústria Mineral e Metalúrgica" não foi um tema abordado pelas Instituições. Tendo em vista a especificidade do tópico, e como o conteúdo é ministrado aos 04 (quatro) Cursos ao mesmo tempo, optou-se por retirá-la da ementa, cabendo ao Professor abordá-la, quando tratar dos tipos de poluição, conforme público alvo. como a carga horária é de 60 horas e que os novos tópicos detectados e propostos podem ser incluídos no conteúdo programático da disciplina, optamos por indicá-los à essa complementação, conforme justificativas a seguir. Logística Reserva, Ergonomia, Metodologia Multicritério, Energia Renovável e Matriz Energética do Brasil e Mundial foram temas sugeridos a serem inseridos, no entanto existem disciplinas que podem assimilar os temas, sendo estas: Logística, Ergonomia, Auxílio Multicritério a Decisão e, Geração e Co-Geração de Energia.

Ecodesenvolvimento foi detectado no estudo comparativo e trata-se de um conceito de desenvolvimento difundido por Ignácio Sachs na década de 70 (Zitske, 2002). No entanto, a ementa da Disciplina já possui Desenvolvimento Sustentável, adotado pela política mundial, através da ONU e vigente nos dias atuais.

Sistemas de Saneamento foi um tema captado que está diretamente relacionado à infraestrutura física e abrange serviços à população, envolvendo meio ambiente e saúde pública (Ribeiro et al., 2010), podendo ser abordado no conteúdo programático.

Estudo de Caso é um recurso didático-pedagógico e que pode ser continuamente adotado como exemplo de casos reais de acontecimentos de impactos ambientais ou mesmo de sistemas de gestão ambiental e outros.

Reutilização da água é um tema a ser abordado em complementação à abordagem dos Impactos Ambientais resultantes da Ação Humana, que no Conteúdo Programático é separada em poluição da água, ar e solo.

Noções e Efeitos da Poluição na Saúde Pública pode ser usado como complementação das informações quando se fala nos Impactos Ambientais resultantes daAção do Homem e suas consequências, conforme explicitado acima.

Ecodesign, segundo Ezio Manzini (Fonte: MMA, 2013) é uma atividade que interliga o técnico ao ambiental, surgindo daí novas propostas socioculturais, é também uma ferramenta de competitividade utilizada pelas empresas, podendo ser abordado dentro do Sistema de Gestão Ambiental. 
Produção mais limpa e Ecoeficiência, sendo a primeira "uma estratégia ambiental preventiva e integrada" aplicada pela empresa (Oliveira; Alves, 2007 apud Anacleto et al., 2012, p. 483), e, a segunda "um processo que direciona os investimentos e o desenvolvimento de tecnologias [...] para minimizar o consumo de recursos e ainda eliminar o desperdício e a poluição" (Schmidheiny, 1996 e Helminen, 2000 apud Anacleto et al., 2012, p. 479), fazem parte dos Sistemas de Gestão Ambiental.

Política de créditos de carbono tratase de um mercado de carbono praticado pelos países em desenvolvimento, instituído pelo Protocolo de Quioto, onde os que conseguem uma redução de gases de efeito estufa recebem uma certificação, e ganham os créditos para negociação com outros países. (Fonte: Portal Brasil/ MMA, 2012).

Pegada de Carbono é utilizada pelas empresas como uma ferramenta para conhecer suas emissões de gases de efeito estufa, e assim reduzi-las (Epstein et al., 2011) podendo ser abordada juntamente aos temas SGA ou mesmo poluição do ar.

Código Florestal, Norma ISO19011, OHAS 18001 e SA 8000 são normas e legislações que fazem parte das certificações das empresas podendo ser abordadas juntamente com Legislação Ambiental e Sistemas de Gestão Ambiental.

Radiação e Radioatividade, são temas específicos das Disciplinas de Física onde "radiação são ondas eletromagnéticas ou partículas que se propagam a uma determinada velocidade" (FIOCRUZ, s.d.) e "radioatividade é a propriedade de determinados tipos de elementos químicos radioativos emitirem radiações" (CNEN, s.d.).

Selo Verde é um programa lançado pela Associação Brasileira de Normas Técnicas (ABNT) de certificação ambiental que atesta quais produtos e serviços são mais ambientalmente amigáveis, fazendo parte de Rotulagem Ambiental.

Reciclagem de Materiais, levantado pelos professores que correlacionam as Discipli- nas com Meio Ambiente, sendo citado anteriormente quando da análise de "Gerenciamento de Resíduos Sólidos” e já abordado no Conteúdo Programático.

Ciclo Hidrogeológico, já consta no tópico Impactos Ambientais quando é abordado Poluição da água, conforme Conteúdo programático da Disciplina.

Serviços ecossistêmicos são "os benefícios diretos e indiretos obtidos pelo homem a partir dos ecossistemas" (Andrade, 2009, p. 9), podendo ser tratado quando da abordagem dos temas "Ecologia e Meio Ambiente".

Introdução de Conceitos e aplicações de "Design for Environment", design for environment é um empreendimento por parte da empresa que envolve saúde, segurança e o meio ambiente na fase de implantação do projeto, com o intuito de reduzir ou evitar os impactos ambientais (Araujo, 2005), podendo ser abordado no tópico de SGA.

Manutenção Industrial, a manutenção pode ser considerada como um diferencial de competitividade dentro da empresa, pois envolve aspectos mecânicos, de serviços, metalúrgicos, entre outros, mas por ser específico não abordaremos na Disciplina.

Perante as discussões e os resultados encontrados, observamos que foi possível atingir os objetivos desta pesquisa, de atualização da Disciplina de Gestão Ambiental e suprir dados que possam complementar a formação profissional com a apresentação da nova ementa e as considerações realizadas.

\section{CONSIDERAÇÕES FINAIS}

Um dos temas que foi identificado no estudo comparativo, Educação Ambiental, não foi discutido no decorrer da discussão, porque as pesquisas possibilitaram a constatação da importância da interdisciplinaridade, conforme preconiza a Resolução CNE $n^{\circ} 02$ de 15 de junho de 2012, que coloca que a EA é uma dimensão da Educação e deve estar presente de forma permanente na Educação Nacional nos níveis da Educação Básica e Superior, devendo ser uma prática contínua e interdisciplinar. 
Sugerimos a inclusão no Conteúdo Programático da Disciplina dos tópicos: "Engenharia, Meio Ambiente, Ecologia e Desenvolvimento Sustentável": Protocolos Internacionais e Serviços Ecossistêmicos; "Legislação Ambiental": Tributação Ambiental, Código Florestal, Normas NBR ISO 19011, OHAS 18001 e SA 8000; "Impactos ambientais - Poluição da Água": Reutilização da água, Sistemas de saneamento; "Poluição do ar": Pegada de carbono, Poluentes Orgânicos Persistentes (POPs) e Saúde Pública; "Poluição do solo": Poluentes Orgânicos Persistentes (POPs) e Saúde Pública; "Controle ambiental - Gerenciamento de Resíduos Sólidos": 3 R's (Reduzir, Reciclar e Reutilizar); "Gestão Ambiental - Sistemas de Gestão Ambiental": Ecodesign, 2 E's (Economy and Environment), Design for Environment, Ecoeficiência, Relatórios de Sustentabilidade e Produção mais limpa; "Rotulagem Ambiental": Política de Crédito de Carbono e Selo Verde.

Uma constatação, perante as pesquisas realizadas, é que se faz necessário ainda mais o envolvimento dos acadêmicos, nas pesquisas científicas realizadas dentro da Instituição, direcionando-as para o meio ambiente. Sob este aspecto, a Universidade se firma em dois dos seus pilares: pesquisa e extensão.

Apesar da pouca participação das empresas, pelas diversidades de ramos de negócios participantes e as sugestões levadas em consideração, acredita-se que será possível o atendimento às empresas de uma maneira geral, capacitando os profissionais para uma efetiva prevenção dos impactos ambientais e responsabilidade social.

Concluindo, reafirmamos que, assim como reconhecem as Organizações, a Instituição de Ensino Superior é a peça chave para promoção do desenvolvimento sustentável, desde que a função de educador seja um compromisso na formação de pessoas críticas, reflexivas e responsáveis com o futuro da nação.

\section{REFERÊNCIAS BIBLIOGRÁFICAS}

ABENGE, Associação Brasileira de educação em Engenharia, Proposta de Diretrizes Curriculares Nacionais para o curso de engenharia, Brasília, jan. 2018

ANACLETO, Cristiane et al. Ecoeficiência e Produção Mais Limpa: Uma Análise das Publicações em Quatro Periódicos Brasileiros da Engenharia de Produção. Disponível em: $<$ www.uff.br/sg/index.php/sg/article/download/ V7N3A15/V7N3A15>. Acesso em: 21 mar. 2018.

ANDRADE, Daniel; ROMEIRO, Ademar. Serviços ecossistêmicos e sua importância para o sistema econômico e o bem-estar humano. 2009. Disponível em: <http:// www. eco.unicamp.br/docprod/downarq. php? $\mathrm{id}=1785 \& \mathrm{tp}=\mathrm{a}>$. Acesso em 21 jun.2018.

ANDRADE, Rui Otávio Bernardes de; TACHIZAWA, Takeshy; CARVALHO, Ana Barreiros. Gestão Ambiental - Enfoque Estratégico Aplicado ao Desenvolvimento Sustentável. 2. ed. São Paulo: Pearson Makron Books, 2002.

ARAÚJO, Silvia Albuquerque Corrêa de. Design for environment nos grandes investimentos e modificações de projeto: processo vinculado ao Sistema de Gestão Integrada da Monsanto Nordeste: UFBA, 2005. 192 p. Dissertação (Mestrado) -PPGTA, DEA, Escola Politécnica. Disponível em: <http://www. teclim.ufba.br/site/material online/dissertacoes/dis_silvia_a_c_de_araujo.pdf $>$. Acesso em: 11 out.2018.

BARDIN, Laurence. Análise de Conteúdo. Tradução por Luís Antero Reto e Augusto Pinheiro. Lisboa: Edições 70, 1977.

BRASIL. Lei $\mathbf{n}^{0} 9.394$ de 20 de dezembro de 1996. Estabelece as Diretrizes e Bases da Educação Nacional. Acesso em 20 out.2018. 
. Lei n⿳0 9.795 de 27 de abril de 1999. Dispõe sobre a educação ambiental, institui a Política Nacional de Educação Ambiental e dá outras providências.. Acesso em 20 out.2018.

.Lei n⿳ $\mathbf{1 2 . 3 0 5}$ de 02 de agosto de 2010 . Institui a Política Nacional de Resíduos Sólidos; altera a Lei no 9.605, de 12 de fevereiro de 1998; e dá outras providências. Acesso em 21 out. 2018.

. Resolução CNE/CP n⿳0 02/2012 de 15 de junho de 2012. Estabelece as Diretrizes Curriculares Nacionais para Educação Ambiental. Diário Oficial da União, Brasília, 18 de junho de 2012 - Seção 1 - p. 70. Acesso em 19 mar.2018.

CNEN. Apostila educativa - Radioatividade. CNEN. Disponível em: <http://www.cnen.gov. br/ensino/apostilas/radio.pdf $>$. Acesso em 21 ago.2018.

EPSTEIN, Dan; SYKES, Judith; CARRIS, Jo. Oficina "Pegada de Carbono". Brasília: 2011. Disponível em: <http://www.mma.gov.br/estruturas/255/arquivos/2_o_que_e_pegada_de carbono_255.pdf $>$. Acesso em 30 set.2018.

FIOCRUZ. Radiação. Disponível em: <http:// www.fiocruz.br/biosseguranca/Bis/lab_ virtual/ radiacao.html>. Acesso em 21 out.2018.

FREIRE, Paulo. Pedagogia da autonomia: saberes necessários à prática educativa. Rio de Janeiro: Paz \& Terra, 1996.

KRAEMER, Maria Elisabeth Pereira. A Universidade do Século XXI rumo ao Desenvolvimento Sustentável. Revista Eletrônica de Ciência Administrativa - ISSN 1677-7387. Faculdade Cenecista de Campo Largo, v. 3, n. 2, nov.2004. Disponível em: <http://revistas. facecla.com.br/index.php/recadm/>. Acesso em 17 mar.2018.

MINISTÉRIO DO MEIO AMBIENTE. Crédito de carbono. Portal Brasil, publicado última modificação 28/05/2012 20:00. . Disponível em: <http://www.brasil.gov.br/meio-ambiente /2012/04/credito-carbono $>$. Acesso em 21 de out.2017.

Ecodesign. Disponível em: $<$ http://www.mma. gov.br/component/k2/item /7654>. Acesso em 21 out. 2017.

ORGANIZAÇÃO DAS NAÇÕES UNIDAS - ONU. Convenção de Estocolmo sobre os Poluentes Orgânicos Persistentes - POPs. PNUMA. Estocolmo: 2004. Ratificada no Brasil pelo Decreto $n^{\circ} 5472$ de 20/06/2005. Disponível em: <http://www.mma.gov.br/estruturas/smcq_seguranca/_publicacao/143 publicacao16092009113044.pdf $>$. Acesso em 30 out. 2017.

. Declaração do Rio sobre Meio Ambiente e Desenvolvimento. Tradução da Rio Declaration, United Nations Conference on Environment and Development, Rio de Janeiro, Brasil, 1992. Disponível em: <http: //pactoglobalcreapr.files.wordpress.com /2010/10/ declaracao-do-rio-sobre-meio-ambiente.pdf $>$. Acesso em 24 nov.2017.

. Recomendações da Conferência Intergovernamental de Educação Ambiental. 1977. Tbilisi. Disponível em: <http://www. meioambiente.pr.gov.br/ arquivos/File/coea/ Tbilisi.pdf $>$. Acesso em 13 mar.2018.

. Relatório Brundtland - "Nosso Futuro Comum". 96 Assembleia Geral das Nações Unidas. A/RES/42/187, dez. 1987. Disponível em: <http://www.un.org/documents/ga/res/42/ ares42-187.htm>. Acesso em 24 mar.2018.

. United Nations Environment Programme (UNEP). Towards a green economy: Pathways to Sustainable Development and Poverty Eradication - A Synthesis for Policy Makers, 2011. Disponível em: http://www. unep.org/green economy/portals/88/documents/ger/GER_synthesis_en.pdf. Acesso em 04 dez.2017. 
. United Nations Educational Scientific And Cultural Organization - UNESCO. Década da Educação das Nações Unidas para um Desenvolvimento Sustentável, EDS, 20052014: documento final do esquema internacional de implementação. Brasília: UNESCO, 2005. 120p. Disponível em <http://unesdoc. unesco.org/images/0013/001399/139937por. pdf $>$. Acesso em 07 dez.2017.

PHILIPPI JR, Arlindo; ROMÉRIO, Marcelo de Andrade; BRUNA, Gilda Collet. (Editores) Curso de Gestão Ambiental. 1. ed. ISBN 85204-2055-9. Barueri, S P: Manole, 2004.

RIBEIRO, Julia Werneck; ROOKE, Juliana Maria Scoralick. Saneamento Básico e sua relação com o Meio Ambiente e a Saúde Pública. Juiz de Fora: UFJF, 2010. 36 p. TCC, Faculdade de Engenharia. Disponível em: $<$ http:// www.ufjf.br/analiseambiental/ files/2009/11/ TCC-SaneamentoeSa\%C3\%BAde. pdf $>$. Acesso em: 31 out.2017.

SILVA, Maurício Gouvêa; SPRITZER, Ilda Maria de Paiva Almeida. A Importância da Sustentabilidade na Formação do Profissional de Engenharia. COBENGE 2010. Disponível em: <http://www.abenge.org.br/ cobenges-anteriores/2010/artigos-2010/artigospublicados_12>.Acesso em: 30 out.2017.

ZITZKE, Valdir Aquino. Educação Ambiental e Ecodesenvolvimento. Revista Eletrônica do Mestrado em Educação Ambiental. ISSN 15171256. Rio Grande, v. 9, jul/dez. 2002. p. 175188. Disponível em: <http://www.fisica.furg.br/ mea/remea/vo19/a13art16.pdf $>$. Acesso em: 12 mar.2018. 